\title{
Structural Unemployment
}

\section{Peter Diamond}

\begin{abstract}
:
Whenever unemployment stays high for an extended period, it is common to see analyses, statements, and rebuttals about the extent to which the high unemployment is structural, not cyclical. This brief views the Beveridge curve pattern of unemployment and vacancy rates and the related matching function as proxies for the functioning of the labor market, and explores issues in that proxy relationship that complicates such analyses.
\end{abstract}

\section{JEL Classifications: E24, E32, E6, J23}

Peter Diamond is an emeritus professor of economics at the Massachusetts Institute of Technology and a visiting scholar at the Federal Reserve Bank of Boston. His e-mail address is pdiamond@mit.edu.

This is a shortened and updated version of Diamond 2013. The author thanks Gadi Barlevy, Olivier Blanchard, Steven Davis, John Haltiwanger, Bart Hobijn, Marianna Kudlyak, Giuseppe Moscarini, Peter Orszag, Jim Poterba, Sarah Bloom Raskin, Robert Triest, Rob Valletta, and participants for their comments, as well as James Fogel and Caroline Shinkle for research assistance.

The views expressed in this brief are those of the author and do not necessarily represent those of the Federal Reserve Bank of Boston, the principals of the Board of Governors, or the Federal Reserve System.

This brief, which may be revised, is available on the web site of the Federal Reserve Bank of Boston at http://www.bostonfed.org/economic/ppb/index.htm.

This version: December 7, 2013 


\section{Introduction}

Much discussion of cyclical and structural unemployment refers to the Beveridge curve, which is made salient by the Bureau of Labor Statistics' monthly publication of the unemployment and vacancy rates that form the curve. ${ }^{1}$ Figure 1 shows the BLS report with data through June 2013. Starting shortly after the trough, all the observations are noticeably above a curve that would fit the observations before and during the recession. That is, we have three observations: (1) unemployment is high, (2) vacancies are low, and (3) unemployment is higher than it was at the same vacancy rates during the recession, or, equivalently, vacancies are higher than they were at the same unemployment rates during the recession. $^{2}$

Analyses using the Beveridge curve typically assume that movements along the curve reflect cyclical effects while shifts in the curve reflect structural effects. These assumptions for interpreting movements along and across curves have been in common use for a long time (see, e. g., Dow and Dicks-Mireaux, 1958). Identification of a shift with structural effects that reduce the potential of stimulative policies depends on whether the cause of/reason for the shift is expected to last long enough to still affect the labor market as the economy recovers and approaches a full-employment point. Thus, for example, shifts in the curve directly attributed to the extension of the duration of unemployment benefits while the economy is weak are recognized as temporary, as the extended benefits are expected to end as the economy recovers. ${ }^{3}$ This does not rule out indirect effects from impacts of extended benefits on labor market outcomes.

Search theory-based analyses of the Beveridge curve typically relate the levels of unemployment and vacancies to the separation rate from employment and a matching function relating the level of hires to the stocks of unemployed and job vacancies. ${ }^{4}$ The separation rate is usually treated as a constant, while the matching function is treated as a given function (often

\footnotetext{
${ }^{1}$ I will use the term "the Beveridge curve" interchangeably for the steady state relationship between unemployment and vacancies and for a curve fitted empirically to observed points. Simple continuous time models generate differential equations that loop around a steady state curve (Blanchard and Diamond, 1990).

${ }^{2}$ I will use the term "the Great Recession" to cover both the NBER-dated recession and the following recovery, which has been marked by continuing high unemployment. This coincides with the term "Long Slump" in Hall (2011).

${ }^{3}$ For analyses of the effects of extended benefits, see, for example, Daly et al (2012), Fujita (2010), Rothstein (2011).

${ }^{4}$ See, for example, Barlevy, 2011, and Blanchard and Diamond, 1989.
} 
Cobb-Douglas) but with a multiplicative efficiency parameter that is allowed to shift to reflect a change in matching efficiency between an earlier Beveridge curve and a later one. However, the separation rate varies over the business cycle, separations vary in the division between quits and layoffs, and separations vary in the extent to which departing workers move to unemployment, to nonparticipation, and directly to other employment (as measured monthly). Similarly, the pattern of hiring from these same three labor market statuses varies over the cycle.

Insofar as these flow patterns differ between recession and recovery and insofar as these vary across different business cycles, the apparent movements of the Beveridge curve will be affected, and one can consider whether a current shift in the curve is likely to last long enough to affect a relevant measure of structural change. In addition, the rates of filling vacancies vary across industries, across firm sizes, and across firm turnover. Thus the distributions of vacancies in these dimensions will affect the measured aggregate matching function, again raising the question of whether a current efficiency parameter of the matching function will be long-lasting. By exploring some of the elements that affect matching and affect the Beveridge curve, this policy memo tries to help identify issues about the possible duration of effects moving the curve at a given time. The focus is on impacts that come from variables that change significantly over the business cycle, rather than trend effects, such as demography, which also shift the curve. Later work will explore some implications of the issues raised here.

The relationship between the matching function and the Beveridge curve is discussed in Section II. Section III considers labor market flows into and out of nonparticipation in the labor force. Section IV considers employment-to-employment flows. Section V considers the speeds of vacancy filling across different dimensions. Concluding remarks are in Section VI.

The focus is on methodology, examining reasons why the current shifts in the Beveridge curve and the matching function might or might not be temporary. While many reasons that complicate interpretation of shifts are identified, their diverse impacts are not quantified. The presentation relies on the existing literature and contains no new empirical analysis. 


\section{The Beveridge Curve and the Matching (Hiring) Function ${ }^{5,6}$}

In a labor market model with only employed and unemployed workers, one can derive a Beveridge curve from a given matching function and a given separation rate. With $m$ as the matching function, a constant-returns-to-scale Cobb-Douglas matching function is:

$$
m[u, v]=A u^{\alpha} v^{1-\alpha} .
$$

With $s$ as the separation rate, for a steady state, equalizing flows into and out of unemployment gives

$$
(1-u) s=A u^{\alpha} v^{1-\alpha}
$$

Solving the Beveridge curve equation for the efficiency parameter of the matching function gives

$$
A=\frac{s(1-u)}{v^{1-\alpha} u^{\alpha}}
$$

If a business cycle is described in terms of a fall in the vacancy rate, followed by a return to its previous value, the observed unemployment and vacancy rates would show a loop around this curve (Blanchard and Diamond, 1990). As long as the labor market's adjustment speed is high, the observed points should lie close to this curve.

A permanent drop in the efficiency parameter, $A$, would result in a shift in the Beveridge curve showing higher unemployment for any vacancy rate. Thus a central question is the extent to which a measured drop in the efficiency parameter during a recession is likely to be longlasting, and so affect a future full-employment point. For example, if the separation rate varies in the course of the cycle, that will shift the Beveridge curve, ceteris paribus. If the separation rate is assumed to be constant, the efficiency parameter, as calculated from the Beveridge curve would show a change. In the case of a separation rate that is lower during a slow recovery, the measured efficiency parameter would be higher. Figure 2 shows the separation rate in monthly data, which varies considerably. Interpreting the change in the Beveridge curve requires consideration of whether the separation rate would return to its earlier level.

\footnotetext{
${ }^{5}$ The term "matching function" has two different uses in the literature. In empirical work, it refers to hiring; in theoretical work, to a meeting of a worker and vacancy, which may or may not result in a hire.

${ }^{6}$ For an intellectual history of the Beveridge curve, see Rodenburg (2011).
} 
For current analyses that use a matching function, the supply function of vacancies plays a part in determining the full employment point. Different matching functions imply different functions relating lags in filling a vacancy to the unemployment-vacancy ratio and thus different supply functions of vacancies. This implies different ratios of unemployment-to-vacancies at different full-employment equilibrium points. ${ }^{7}$ As a result, a downward shift in the efficiency parameter of the matching function generates a larger structural component than if the fullemployment level of unemployment were exogenous.

The change in unemployment from the prior full-employment point to the current unemployment rate can be divided in two. The difference between prior and future fullemployment points can be considered structural, while the difference in unemployment between the future full-employment point and the currently observed unemployment rate can be considered cyclical. That is, the latter gap, between the current unemployment rate and the target future full-employment point, is a measure of what might be addressed by stimulus policies when assuming that the shift in the Beveridge curve is a structural, longlasting shift.

For chosen values of $\mathrm{s}$ and $\alpha$, fitting the structure of the Beveridge curve discussed above to unemployment and vacancy rates yields a value of the matching function efficiency parameter, A. Alternatively, the matching function can be estimated directly using hiring data, along with unemployment and vacancies. Figure 3 shows the efficiency parameter estimated in Barlevy (2011). ${ }^{8}$ Barlevy noted that: “as evident from [this] Figure, match productivity using data on new hires starts to fall around December 2007, considerably before any indications of a shift in the Beveridge curve relating unemployment and vacancies” (p. 89). Furthermore, the estimated matching function efficiency parameter stops its significant decline about the time the Beveridge curve starts shifting out. This raises the issues of whether a decline in the matching function is part of the normal Beveridge curve pattern in a recession, or at least in this recession, and what additional factors influence the relationship between the Beveridge curve and the matching function. Section V looks at some of the factors underlying the aggregate matching function.

\footnotetext{
${ }^{7}$ Barlevy (2011) contains such a calculation.

${ }^{8}$ For another analysis of the efficiency parameter of the matching function, using help-wanted data for vacancies, see Barnichon and Figura (2011a, b). They find that the matching function efficiency parameter has a cyclical component over the period 1967-2006.
} 
Analysis using the model above with only two labor market statuses will be affected by variations in the patterns of both hiring and separations relative to nonparticipation as well as changes in the rates of movement directly between unemployment and nonparticipation. Similarly, analysis using a model that ignores employment-to-employment (E-E) flows will be affected by variations in the patterns of both quits (as part of separations) and the hiring of the already employed. Shifts in these patterns may be permanent or may return to their previous pattern as the economy recovers. This possibility calls for a more detailed study of pattern movements and an exploration of two questions: (1) the extent to which the rate and function will return to earlier values during the recovery; and (2) the extent to which the movements during the recession and early portions of the recovery differ from past cycles because the current cycle is deeper and longer and stemfrom causal factors that were not present in previous cycles. The next section reviews some of the patterns over recent cycles.

\section{Nonparticipation}

The unemployed make up only a fraction of new hires, as newly hired workers include labor market nonparticipants (those outside the labor force) and workers already employed as of the previous interview. Thus the matching function is a relationship between hiring and two proxy variables for the demand and supply of new hires. The relationship would change if the omitted variables changed their patterns relative to the proxy variables of unemployment and vacancy rates. It would also change if disaggregation of vacancies implied a changed relationship between the aggregates. Similarly, with different hazards of finding jobs by duration of unemployment, a change in the distribution of durations of unemployment may alter the relationship between the aggregates, depending on the causes of the differences in job-finding hazards. This section examines how the hiring of nonparticipants affects the measurement of the matching function and considers the flows between nonparticipation and unemployment. The next considers hiring of the already employed. Disaggregation of vacancies is discussed in Section IV.

\section{Flow of Nonparticipants into Employment}

Studies of worker flows have long reported on the sizable flows among all three categories, of 
employed, unemployed, and nonparticipants. Errors in the classification of workers that are not important for measuring the stocks are, however, important for measuring the flows and several approaches, which give broadly similar results, have been taken to adjust the data for misclassification. Figure 4 shows the average adjusted and unadjusted monthly flows for the period October 1995 to September 2012. Note that the large adjustments for misclassification involve nonparticipants. Using the adjusted flows, on average over this period, 2.0 million workers went from being classified as unemployed one month to employed the next (a U-E flow), and a number nearly as large (1.7 million) went from being classified as nonparticipants one month to being employed the next month (an N-E flow). Thus the stock of unemployed used in both the Beveridge curve and the matching function serves as a proxy variable for the availability of nonemployed workers to move into employment. Note that the number of nonparticipants who report that they want a job is a sizable fraction of the number of unemployed. The reasonable quality of the overall fit of the standard matching function, on average, speaks to the degree of stability of the overall proxy relationship. Indeed the strong similarity in Beveridge curves drawn using the standard unemployment rate (shown in Figure 1 above) and using the U-6 unemployment rate (shown in Figure 5) speaks to the stability of the relationship in general terms. The U-6 measure is: total unemployed, plus all persons marginally attached to the labor force, plus total employed part time for economic reasons, calculated as a percent of the civilian labor force plus all persons marginally attached to the labor force. ${ }^{9}$

Similar to comparing Beveridge curves using unemployment and the U-6 measure would be comparing estimated matching functions using just unemployment and using a weighted sum of the different elements in the U-6 measure. ${ }^{10}$ However, just as differences between the Great Recession and earlier recessions and recoveries could show up as a shift in the standard matching function, so, too, could changes in hiring outcomes show up as a different set of weights on the different groups of employed and nonemployed workers in a broader matching function. Indeed a key question for interpreting the current circumstances is the extent to which we expect different outcomes given the differences across recessions-in severity, in

\footnotetext{
${ }^{9}$ Persons marginally attached to the labor force are those who currently are neither working nor looking for work but indicate that they want and are available for a job and have looked for work sometime in the past 12 months. Discouraged workers, a subset of the marginally attached, have given a job-market related reason for not currently looking for work. Persons employed part time for economic reasons are those who want and are available for fulltime work but have had to settle for a part-time schedule.

${ }^{10}$ For an exploration of the use of a weighted sum of different pools of labor, see Blanchard and Diamond (1989, 1990).
} 
length, in the state of financial firms, in the state of the housing market, and in fiscal positions of state and local governments. ${ }^{11}$

Figure 6 shows the time series since February 1990 of the ratio of the aggregate flow into employment from nonparticipation relative to that from unemployment. With a large increase in the number of unemployed during recessions, the flow from unemployment to employment went up rapidly during the recessions shown and then stopped rising and, sometime afterwards, started falling. In contrast, the N-E flow, from nonparticipation to employment, varied less than the U-E flow and tended to fall during the recessions and then to start slowly rising, more slowly than the flow from unemployment was declining. Thus Figure 6 shows a sharp drop in the NE/UE ratio during the recessions and slow rises afterwards. By itself, this pattern in the NE/UE ratio would tend to fit with a decline in the total amount of hiring relative to the numbers of unemployed, and so a sharp decline in the estimated matching function efficiency parameter in a typical recession, followed by a rising efficiency parameter after the trough. The NE/UE ratio peaked earlier than the start of the Great Recession and is still very low compared with the earlier available data. Comparing Figures 3 and 6 , the timing of the decline in the efficiency parameter is roughly in line with the fall in NE/UE, but after that, the efficiency parameter is roughly constant while the NE/UE ratio was rising, but still low.

\section{Flow of Employed Workers into Nonparticipation}

The division of the flow out of employment between nonparticipation and unemployment affects the stock of unemployed and so affects the Beveridge curve. The ratio of the flow from employment to nonparticipation relative to the flow to unemployment is shown in Figure 7. The flow into unemployment went up rapidly during the recession, as with the two earlier recessions in the data, but to a much greater extent. Then the flow showed a steady drop during

\footnotetext{
${ }^{11}$ Another approach to the diversity of positions of new hires is to use a three-dimensional analog to the Beveridge curve, using a measure of the relevant portion of the nonparticipants, along with unemployment and vacancy rates, as has been done in Veracierto (2011), which considered three-state models, contrasting the results to two-state models. Summarizing the data in Figure 14 of the paper, Veracierto reports that: "these transition rates were relatively stable prior to 2007:12. However, we see that with the onset of the recession, there was a significant drop in the transition rate from nonparticipation to employment, a drop in the transition rate from unemployment to nonparticipation, a large increase in the transition rate from nonparticipation to unemployment, and a large increase in the transition rate from employment to unemployment. In turn, the transition rate from employment to nonparticipation was not significantly affected." The paper appears to use unadjusted flow numbers.
} 
the recovery, again similar to the two previous recessions. However, given the magnitude of the rise, the flow out continued to be much higher than before the recession, unlike the two other recessions. In contrast, the flow into nonparticipation went down, not up, during the Great Recession and then did not change much. Thus, there was a sharp drop in the EN/EU ratio in all three of the recent recessions. The Great Recession, being more severe and longer-lasting, has had a much larger and more extended decrease in that ratio. The rise in the ratio during the recovery has only restored a fraction of the previous decline.

\section{Flows between Nonparticipation and Unemployment}

The division of the flow out of employment between nonparticipation and unemployment affects the stock of unemployed and so affects the Beveridge curve. Also relevant are the flows between unemployment and nonparticipation. While the two flows changed a lot, there was considerable parallel shape in the movements and so the ratio, which rose during the recession and then fell, did not vary as much as the ratio of the flows from employment. The difference shows a somewhat higher level flowing into unemployment than in the period before the start of the recession, but the difference is not very large.

Kudlyak and Schwartzman (2012) analyze the direct effect of the four flows involving nonparticipation on the unemployment rate. ${ }^{12}$ They consider the six hazard rates defined by the six flows among $\mathrm{E}, \mathrm{U}$, and $\mathrm{N}$ and use the steady state approximation to the stocks, given these flows. Then they ask how the unemployment rate would be different if the four hazard rates involving nonparticipation remained as they were before the recession, while the hazard rates between employment and unemployment followed the actual empirical pattern. Figure 8 shows their calculation for four recessions, summarized in their paper as follows:

We find that in the 2007-2009 recession, had flows [rates] in and out of nonparticipation remained constant, the aggregate unemployment rate would have increased by 3 percentage points, while the actual unemployment rate increased by 5.5 percentage points. The flows to and from nonparticipation also accounted for a substantial part of the persistence of unemployment during the recovery. Two years after the 2009 unemployment peak, the counterfactual aggregate unemployment rate would have been 2 percentage points higher than at the start of the rise in unemployment, while the actual unemployment rate is 4 percentage points higher. In

\footnotetext{
${ }^{12}$ The authors have pointed out that their analysis does not include an adjustment for misclassification.
} 
contrast, in the 1981-1982 recession, the counterfactual aggregate unemployment rate increases by 2.5 percentage points, while the actual unemployment rate increased by 3.75 percentage points. Two years after the 1982 unemployment peak, the counterfactual aggregate unemployment rate and the actual unemployment rate were equal to the rate at the start of the rise in unemployment. ${ }^{13}$ (pp. 1-2)

In sum, they conclude from this source that "the data indicate that, compared to previous recessions, the 2007-2009 recession is characterized by a particularly large increase in the unemployment rate and by a particularly slow decline in the unemployment rate from its peak" (p. 9).

Several factors are likely to have combined to generate these patterns. The large extension of unemployment benefits is likely to have increased the extent of remaining in measured unemployment rather than leaving the labor force. The impact on aggregate hiring from this effect is plausibly not large given the availability of so many unemployed per vacancy throughout most of the economy, a view supported by some studies cited in footnote 4 . In any event, this part of the effect is likely to go away when extended benefits end, as is likely to occur once the economy recovers.

The depth and length of the Great Recession have contributed to a very large increase in the pool of long-term unemployed and so this likely has affected the makeup of the pool of job losers, which presumably includes more people with a stronger attachment to the labor force than is the case in the usual recession. By increasing the stock of unemployed, this pattern would contribute to a shift in the Beveridge curve. Thus a key question is whether the flow into long-term unemployment will return to a more typical pattern as the economy recovers.

Also relevant is whether worker experience of more time spent in unemployment and less time spent in nonparticipation has current effects or may have lasting effects. That is, if someone who would otherwise be a nonparticipant is behaving in a way that qualifies for the label unemployed, how much does the contribution to hiring change? It seems that it need not be all the difference in the usual recession. As to the long-run effects, experiencing long-term

\footnotetext{
${ }^{13}$ Footnote in original: "The unemployment rate is a nonlinear function of the six transition rates. Thus, our work shares the same criticism as some other works (for example, Shimer (2012)) that the values of the counterfactual depend on the values at which we fix the transition rates.”
} 
nonemployment matters. Whether a long spell of nonemployment has a different long-run effect if some of it is nonparticipatory rather than unemployed does not seem likely to make a difference.

\section{Employment-to-Employment Flows}

A similar issue for the measurement of the matching function comes from the hiring of those already employed, as workers who are employed one month are often with a different employer the following month, an E-E flow. Figure 9 (updated data, following Fallick and Fleischman, 2004) provides the relative sizes of different flows over the period from October 1995 to September 2012, although the table includes no adjustments for misclassification, presumably a much bigger issue with change in status than with E-E flows. ${ }^{14}$ The table reports the flows in two ways. The top of the table relates the flows to population, and so gives the relative sizes of the absolute flows. Note that the E-E flow of 1.4 percent of the population is larger than the unadjusted U-E flow and almost as large as the unadjusted N-E flow. From the relative sizes of adjusted and unadjusted flows in Figure 4, assuming no significant adjustment in the E-E flow is called for, the flow considerably exceeds either of the other two flows into employment, emphasizing the proxy nature of the structure of both the Beveridge curve and the matching function. While one could examine matching functions for the separate flows into employment from the three sources, the hiring rates would depend on all three classifications of workers seeking employment or a change in employer.

Using quarterly data, tabulated on a recently constructed multi-state pilot database, Hyatt and McEntarfer (2012) report on the time series of flows out of employment to other jobs and to nonemployment (Figure 10). The flow from job to job that is without an in-between nonemployment spell shows a sharp drop during the Great Recession and a continued very low level. This is consistent with the large drop in quits during the recession, and the slowly rising, but still low, level of quits during the recovery as shown in Figure 11. Thus we appear to have a period where E-E flows are way down, as are N-E flows, but not U-E flows. From the decline in quits and E-E flows we can conclude that the relevant stock of

\footnotetext{
${ }^{14}$ Moscarini and Thomsson (2007) analyze CPS data for 1994-2006 and "revise upward current estimates of the EE flow from $2.7 \%$ to $3.2 \%$ per month” (p. 809). Nagypal (2008) also discusses data adjustments.
} 
employed available for hiring may be down considerably, although part-time work for those preferring full-time work is up. As in the consideration of the nonparticipants above, this is consistent with a decline in the measured efficiency parameter of the standard matching function during the recent recession and a continued low level of the efficiency parameter during the recovery, but not directly with further declines. Again there is no apparent reason to think this pattern would be long-lasting once the economy recovers. As noted by Davis, Faberman and Haltiwanger (2012a) and shown in Figure 12, while layoffs are highly correlated with job destruction, quits and job destruction tend to move in opposite directions. Quits often result in a new vacancy to replace the worker who has left. The impact of such quits on the hiring rate is discussed in the next section.

\section{Filling of Vacancies}

Disaggregated data on the filling of vacancies across firms and industries suggest that changes in the pattern of vacancies over the business cycle can affect the measurement of the matching function.

The standard matching function relates the flow of hires to the stocks of unemployed and vacancies, although some studies have included additional variables. The Job Openings and Labor Turnover Survey (JOLTS) provides monthly estimates of hiring, both aggregated and disaggregated. Roughly 16,000 business establishments are asked for the number of hires (and separations) that occurred during the month as well as the numbers of employed and vacancies for a single point in the month (the pay period including the 12th of the month and the end of the month, respectively). ${ }^{15}$ The Current Population Survey (CPS) asks roughly 60,000 households about the labor force status of their members during the survey reference week (usually the week that includes the 12th of the month). Thus an estimate of the matching function based on the JOLTS and the CPS relates hiring during the month to unemployment and vacancy levels at a point in the month (and/or in the prior month).

Davis, Faberman, and Haltiwanger (2012b) analyze the establishment-level data for the

\footnotetext{
${ }^{15}$ A job opening requires that: 1) a specific position exists and there is work available for that position, 2) work could start within 30 days regardless of whether a suitable candidate is found, and 3) the employer is actively recruiting from outside the establishment to fill the position. Included are full-time, part-time, permanent, shortterm, and seasonal openings. Active recruiting means that the establishment is taking steps to fill a position by advertising in newspapers or on the Internet, posting help-wanted signs, accepting applications, or using other similar methods.
} 
period from the start of the data in December 2000 through December 2006, and look at published data through December 2011. They find that the speed of filling a vacancy varies by industry, by firm size, by turnover, and by firm growth, and that the proportion of hiring in different industries varies significantly over the business cycle. Thus the aggregate matching function should vary with changes in the distribution of vacancies in multiple dimensions.

Complicating the picture is the fact that much hiring happens without triggering a measured vacancy. In terms of basic measurement, Davis, Faberman, and Haltiwanger report that "Employers with no recorded vacancies at month's end account for $45 \%$ of aggregate employment. At the same time, establishments reporting zero vacancies at month's end account for $42 \%$ of all hires in the following month." Of course, there can be hiring after a posted vacancy is filled quickly enough that the hire appears in the data for the month but the vacancy did not appear at the date when outstanding vacancies were measured. Also there appears to be hiring taking place without a corresponding posted vacancy, a case of taking advantage of an opportunity to hire. These observations indicate the proxy role of measured vacancies for the matching function, as well as the proxy measure of unemployment, as argued above.

Davis, Faberman, and Haltiwanger disentangle the within-month time structure for the posting and filling of vacancies by modeling a smooth discrete-time daily process, selecting daily parameters that are consistent with the observed monthly data, and assuming that all hires follow a vacancy. The model succeeds in accounting for two-thirds of the hires in establishments without reported vacancies, suggesting that hiring without a posted vacancy is significant, albeit less so than in the raw data. While they report multiple measures of vacancy filling, Figure 13 reports only the mean time to fill a vacancy across three different groupings of firms. They find significant differences in the speed with which vacancies are filled on average across industries-the mean time to fill a vacancy is 8.3 days in construction and 35.4 days in health and education. These are two sectors that have different hiring experiences in typical recessions and recoveries, and particularly so in the Great Recession. It was well recognized that employment in construction fell strongly and recovery in construction would be slower than in the usual recession after the considerable overbuilding before the Great Recession (e.g., Hall, 2011). But, given widespread high unemployment relative to vacancies throughout the economy, it is not clear that this observation about construction seriously affects the standard analysis of the labor market effects of a stimulus program. The fall in 
construction hiring should affect the measured matching function efficiency parameter without implying a lasting change in the parameter, beyond any continuation of trend effects, once relative hiring returns to something similar to the previous relative industry hiring pattern.

The mean time to fill a vacancy in firms with fewer than 250 employees is roughly half the rate at firms with at least 1,000 employees. Moscarini and Postel-Vinay (2012) argue that "The differential growth rate of employment between large and small U.S. firms is strongly negatively correlated (in deviations from trend) with the contemporaneous unemployment rate” (p. 2509). This pattern should affect the aggregate matching efficiency parameter increasing it with high unemployment and lowering it with low unemployment. The paper includes discussion of the 2009-2010 period. The relative performance of small firms early in the recession (2008:IV) was poor, compared to previous recessions, in line with the credit channel idea. But in 2009, already small firms did rebound, relative to large firms. Ever since, large firms have created very little net employment growth. Most of job creation since 2010 is from small firms. In addition, both the vacancy rate and the vacancy filling rate of large establishments in JOLTS fell during the recession much more than at small establishments. Since 2010, this composition effect would contribute to an increase in aggregate matching efficiency parameter. ${ }^{16}$

In the third category shown in Figure 13, Davis, Faberman, and Haltiwanger report that mean duration varies by a factor of ten across quintiles sorted by turnover ratio. Presumably quits occur disproportionally in higher turnover firms. Thus the continuing drop in quits in the Great Recession is plausibly linked to a relative drop in the number of vacancies at higher turnover firms, and so constitute a further source of decline in the aggregate matching efficiency parameter. The slow recovery of quits would limit the rise of the parameter during the current recovery. The three categories of diversity in hiring rates are not simply additive, but include overlap as the turnover rate plausibly varies with firm size and both of these factors vary by industry. While the examples in Figure 13 refer to firms, consideration across occupations is in Hobijn (2012), which uses CPS, JOLTS, and state-level job vacancy surveys that cover about 10 percent of the labor force to produce annual vacancy and hires estimates (and so vacancy yields) for 2005 through 2011. He finds 'a lot of variation in job openings

\footnotetext{
${ }^{16}$ There is an important pattern of hiring relative to the ages of firms. Presumably the pattern of hiring by a firm's age varies in typical cycles and may have varied differently in the Great Recession. This would be interesting to explore.
} 
rates and vacancy yields across occupations' and that 'the shift in occupation mix of job openings and hires since 2007 accounts for the bulk of the decline in measured aggregate match efficiency” (pp. 4-5).

\section{Recruiting Intensity}

Davis, Faberman and Haltiwanger (2012b) note the very strong cross-section pattern showing that firms that do more hiring have a higher yield per vacancy, seen in Figure 14. This pattern presumably interacts with other factors in determining the speeds of filling vacancies shown in the figure. They argue that:

One possibility is that employers act on other margins using other instruments, in addition to vacancies, when they increase their hiring rate. They can increase advertising or search intensity per vacancy, screen applicants more quickly, relax hiring standards, improve working conditions, and offer more attractive compensation to prospective employees. If employers with greater hiring needs respond in this way, the job-filling rate rises with the hires rate in the cross section and over time at the employer level. (p. 20)

In addition, workers may focus both their search and their willingness to accept a job on firms expected to grow, as the long-term employment possibilities there may look more attractive. Davis, Faberman and Haltiwanger refer to modeling this pattern as incorporating "recruiting intensity.” As recruiting intensity is not readily available as a variable, they multiply vacancies by a proxy measure for average recruiting intensity to obtain a measure of effective vacancies. They model effective vacancies as vacancies multiplied by the aggregate hires rate raised to the power $\varepsilon$. To analyze aggregate matching they then use the standard Cobb-Douglas matching function, but using effective vacancies.

Davis, Faberman and Haltiwanger use a calibrated simulation approach, taking values of $\alpha=0.5, \varepsilon=0.82$ and $A$ chosen to equate the mean value of the theoretically implied vacancy yield to the empirical vacancy yield. They find a better fit than with the standard matching function: "our recruiting intensity measure explains about one quarter of the aggregate time-series residuals produced by the standard matching function, residuals that other authors interpret in terms of mismatch or fluctuations in matching efficiency” (2012b, pp. 4-5). They 
also examine the behavior in the Great Recession of recruiting intensity, $G^{\varepsilon}$. Figure 15 [their Figure I] "plots national time series for the job-filling rate and recruiting intensity per vacancy. The job-filling rate rose sharply, from 4.4 percent per day in December 2007 to a peak of 6.6 percent per day in August 2009. It fell steadily thereafter, though it remains above prerecession levels at 4.8 percent per day as of September 2011. Recruiting intensity per vacancy fell sharply during the Great Recession, declining by over 21 percent between December 2007 and its trough. It remains 11 percent below its pre-recession level as of September 2011” (2012c, p. 4). Note that recruiting intensity started declining before the start of the recession, consistent with the timing discussion of Barlevy's analysis discussed above.

Thus the drop in recruiting intensity, working against the effect of the rise in unemployment per vacancy on the rate of job filling, pushed down the measured efficiency parameter of the standard matching function. The magnitude of the effect of using their generalized matching function can be seen in Figure 16 (Figure 1 in their 2012b) which calculates the vacancy yield - hires divided by vacancies-comparing the empirical level with those coming from the standard and generalized functions. Thus recognizing recruiting intensity offsets some of the decline in matching, but only a fraction. Presumably recruiting intensity will recover when the economy recovers.

Another perspective on recruiting intensity comes from the difference, noted above, between meetings of job candidates with job openings and an actual hiring. The speed of filling a vacancy depends on the time to evaluate candidates and the tradeoff between hiring one of the current applicants and waiting to examine further applicants. As the tightness of the labor market changes, so too do the reservation wages and reservation match qualities on both sides. It is plausible that the sheer number of applicants per vacancy and the range of applicant qualities are likely to be higher given the depth and length of the current period of a weak economy, leading to a slower hiring process, at least at large firms receiving many applications. Indeed there has been such a claim based on a survey of large firms by the Corporate Executive Board (Light, 2011).

\section{Concluding Remarks}

The Beveridge curve gives a quick picture of what is happening in the labor market. As with any quick picture, any policy inferences are made by relying on explicit or implicit models of the 
working of the economy. This essay has explored issues raised by digging below the aggregate statistics and the simple aggregative model to learn more about the workings of the labor market, and so the appropriateness of different inferences.

This essay found multiple reasons for the measured efficiency parameter of the matching function to vary over a business cycle, and reasons for that variation to be different from earlier recessions and recoveries given the nature of the Great Recession. Unfortunately, the essay did not contain a net impact from quantifying the many effects identified and their likely extent of continuance. In short, merely noticing a shift in the Beveridge curve, as shown in Figure 1, is not a good basis for a conclusion that further stimulus policy is not appropriate; measuring structural change is not simple or easy.

Presentations of the aggregate matching function often cite the aggregate production function as a parallel construction that has proven useful. However, in considering the relationship between aggregate output and aggregate inputs, many macroeconomists make a sharp distinction between trend issues and cycle issues. Trend is addressed through a Solow production function; the cycle through Okun's law. ${ }^{17}$ This essay suggests development of a similar division for analysis of the labor market, in that the efficiency parameter of the standard aggregate matching function should vary in the course of a cycle. Support for this perspective comes from the disaggregated work of Davis, Faberman, and Haltiwanger, and from the cyclic variation in the relative hiring from the already-employed and the labor force nonparticipants. ${ }^{18}$ The bottom line is that the Beveridge curve has important information on the state of the labor market, but should not be viewed as a tight technical relationship and inferences should be based on the underlying factors behind the unemployment and vacancy observations.

\footnotetext{
${ }^{17}$ See, e.g., Ball, Leigh, and Loungani (2012).

${ }^{18}$ For an analysis of cycles and trends in the matching function efficiency parameter, see Barnichon and Figura (2012).
} 


\section{References}

Ball, Laurence, Daniel Leigh, and Prakash Loungani. 2012. “Okun's Law: Fit at 50?” Available at http://www.imf.org/external/npr'res/seminars/2012/arc/pdf/BLL.pdf.

Barlevy, Gadi. 2011. "Evaluating the Role of Labor Market Mismatch in Rising Unemployment.” Economic Perspectives 35(3): 82-96.

Barnichon, Regis, and Andrew Figura. 2011a. "What Drives Matching Efficiency? A Tale of Composition and Dispersion.” Finance and Economics Discussion Series 2011-10.

Washington, DC: Board of Governors of the Federal Reserve System.

Barnichon, Regis, and Andrew Figura. 2011b. "Labor Market Heterogeneities, Matching Efficiency, and the Cyclical Behavior of the Job Finding Rate.” Unpublished.

Barnichon, Regis, and Andrew Figura. 2012. "The Determinants of the Cycles and Trends in U.S. Unemployment.” Unpublished working paper. Available at http://www.bde.es/investigador/papers/sie1212.pdf.

Blanchard, Olivier Jean, and Peter Diamond. 1989. “The Beveridge Curve.” Brookings Papers on Economic Activity 1: 1-76.

Blanchard, Olivier Jean, and Peter Diamond. 1990. “The Aggregate Matching Function.” In Growth, Productivity, Unemployment: Essays to Celebrate Bob Solow's Birthday, ed. Peter Diamond, 159-201. Cambridge, MA: The MIT Press.

Daly, Mary C., Bart Hobijn, Ayş egül Sahin, and Robert G. Valletta. 2012. "A Search and Matching Approach to Labor Markets: Did the Natural Rate of Unemployment Rise?” Journal of Economic Perspectives 26(3): 3-26.

Davis, Steven J., R. Jason Faberman, and John C. Haltiwanger. 2012a. "Labor Market Flows in the Cross Section and Over Time.” Journal of Monetary Economics 59(1): 1-18.

Davis, Steven J., R. Jason Faberman, and John C. Haltiwanger. 2012b. "The Establishment Level Behavior of Vacancies and Hiring.” Working Paper No.16265, revised August 2012. Cambridge, MA: National Bureau of Economic Research.

Davis, Steven J., R. Jason Faberman, and John C. Haltiwanger. 2012c. "Recruiting Intensity During and After the Great Recession: National and Industry Evidence.” American Economic Review 103(3): 584-588.

Diamond, Peter. 2013. “Cyclical Unemployment, Structural Unemployment.” IMF Economic Review 61(3): 410-455.

Dow, J. Christopher R., and Louis A. Dicks-Mireaux. 1958. "The Excess Demand for Labour: A Study of Conditions in Great Britain, 1946-56." Oxford Economic Papers 10(1): 1-33. 
Fallick, Bruce, and Charles A. Fleischman. 2004. "Employer-to-Employer Flows in the U.S. Labor Market: The Complete Picture of Gross Worker Flows.” Finance and Economics Discussion Series 2004-34. Washington, DC: Board of Governors of the Federal Reserve System.

Fujita, Shigeru. 2010. "Effects of the Unemployment Insurance Benefit Extensions: Evidence from the Monthly CPS.” Federal Reserve Bank of Philadelphia, Working Paper 10-35. Philadelphia: Federal Reserve Bank of Philadelphia.

Hall, Robert E. 2011. “The Long Slump.” American Economic Review 101(2): 431-469.

Hobijn, Bart. 2012. “The Industry-Occupation Mix of U.S. Job Openings and Hires,” Working Paper 2012-09. San Francisco: Federal Reserve Bank of San Francisco.

Hyatt, Henry, and Erika McEntarfer. 2012. “Job-to-Job Flows in the Great Recession.” American Economic Review 102(3): 580-583.

Kudlyak, Marianna, and Felipe Schwartzman. 2012. “Accounting for Unemployment in the Great Recession:Nonparticipation Matters.” Working Paper 12(4). Richmond:

Federal Reserve Bank of Richmond..

Light, Joe. 2011. “Corporate News: Jobs Open, but Hiring Remains Slow-Recruiters Say They Have Trouble Finding Candidates for Skilled Positions, and Managers Hold for Better Prospects.” Wall Street Journal, March 7, 2011.

Moscarini, Giuseppe, and Fabien Postei-Vinay. 2012. "The Contribution of Large and Small Employers to Job Creation at Times of High and Low Unemployment.” American Economic Review 102(6): 2509-2539.

Moscarini, Giuseppe, and Kaj Thomsson. 2007. “Occupational and Job Mobility in the US.” Scandinavian Journal of Economics 109(4): 807-836.

Nagypál, Éva. 2008. "Worker Reallocation over the Business Cycle: The Importance of Employer-to-Employer Flows.” Available at http://faculty.wcas.northwestern.edu/ een461/JJempirical_2008_0207.pdf.

Rodenburg, Peter. 2011. "The Remarkable Transformation of the UV Curve in Economic Theory.” European Journal of the History of Economic Thought 18(1): 125-153.

Rothstein, Jesse. 2011. "Unemployment Insurance and Job Search in the Great Recession." Brookings Papers on Economic Activity 2: 143-209.

Shimer, Robert. 2012. "Reassessing the Ins and Outs of Unemployment.” Review of Economic Dynamics15 (6): 1319-1338.

Veracierto, Marcelo. 2011. "Worker Flows and Matching Efficiency.” Economic Perspectives, 35(4): 147-169. 
Figure 1: The Beveridge Curve (job openings vs. unemployment rate) (Seasonally adjusted)

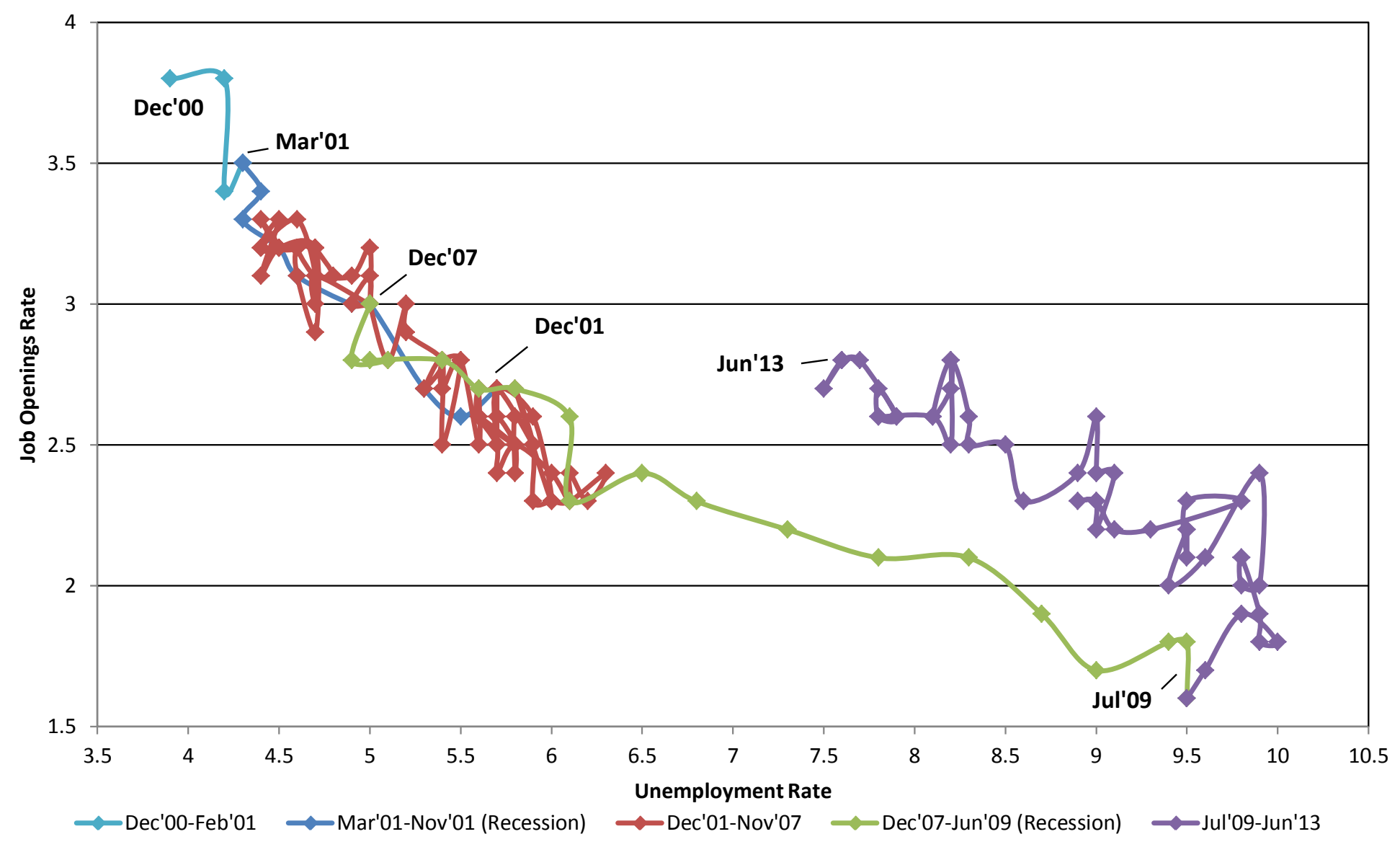

Source: Bureau of Labor Statistics, Current Population Survey and Job Openings and Labor Turnover Survey, August 23, 2013. 
Figure 2: Separation Rate, 2000:12-2013:6

Three-Month Moving Average

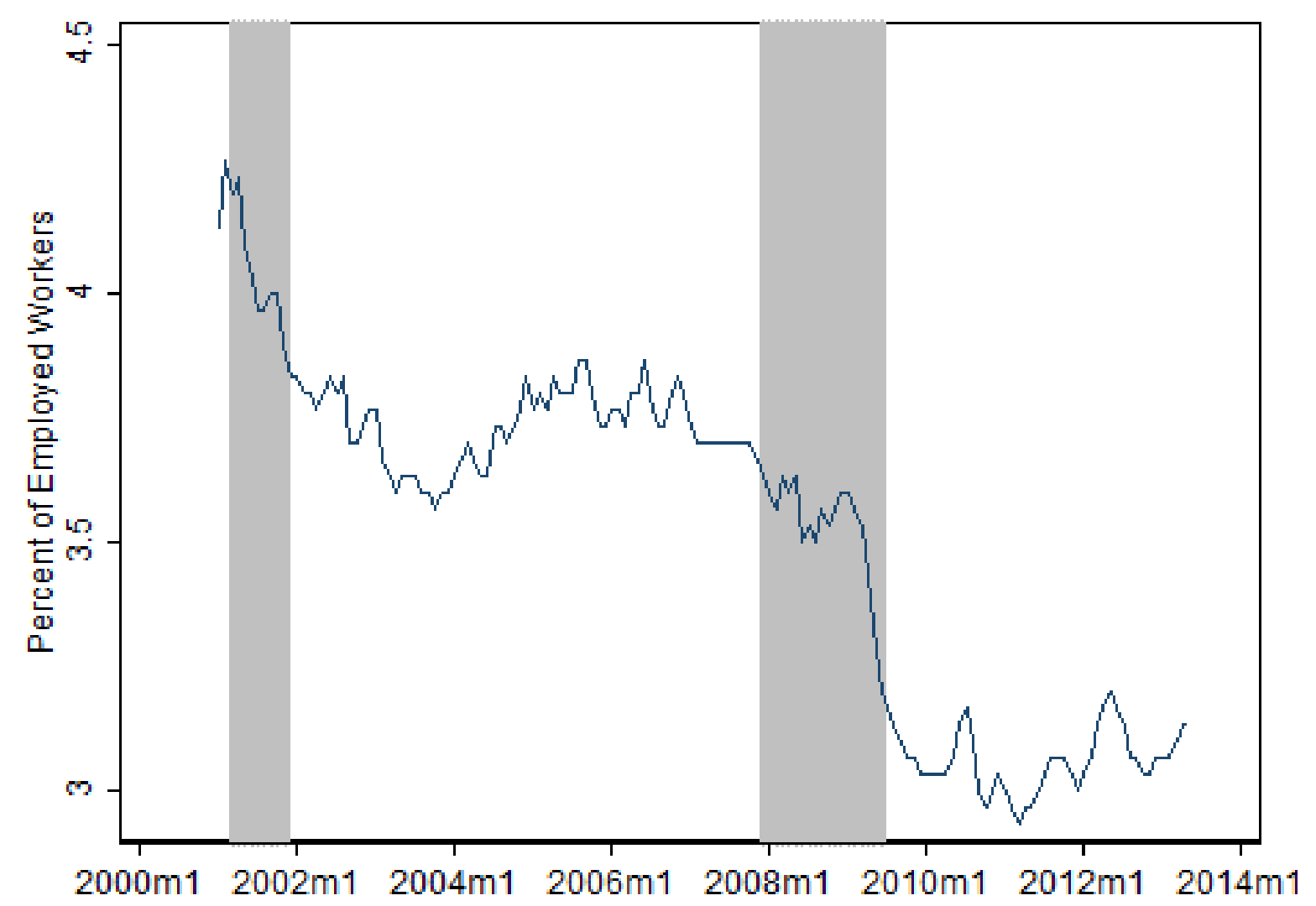

Source: Bureau of Labor Statistics, Current Population Survey, and Job Openings and Labor Turnover Survey, August 26, 2013. 
Figure 3: Implied Match Productivity Using Data on New Hires, 2001-2011

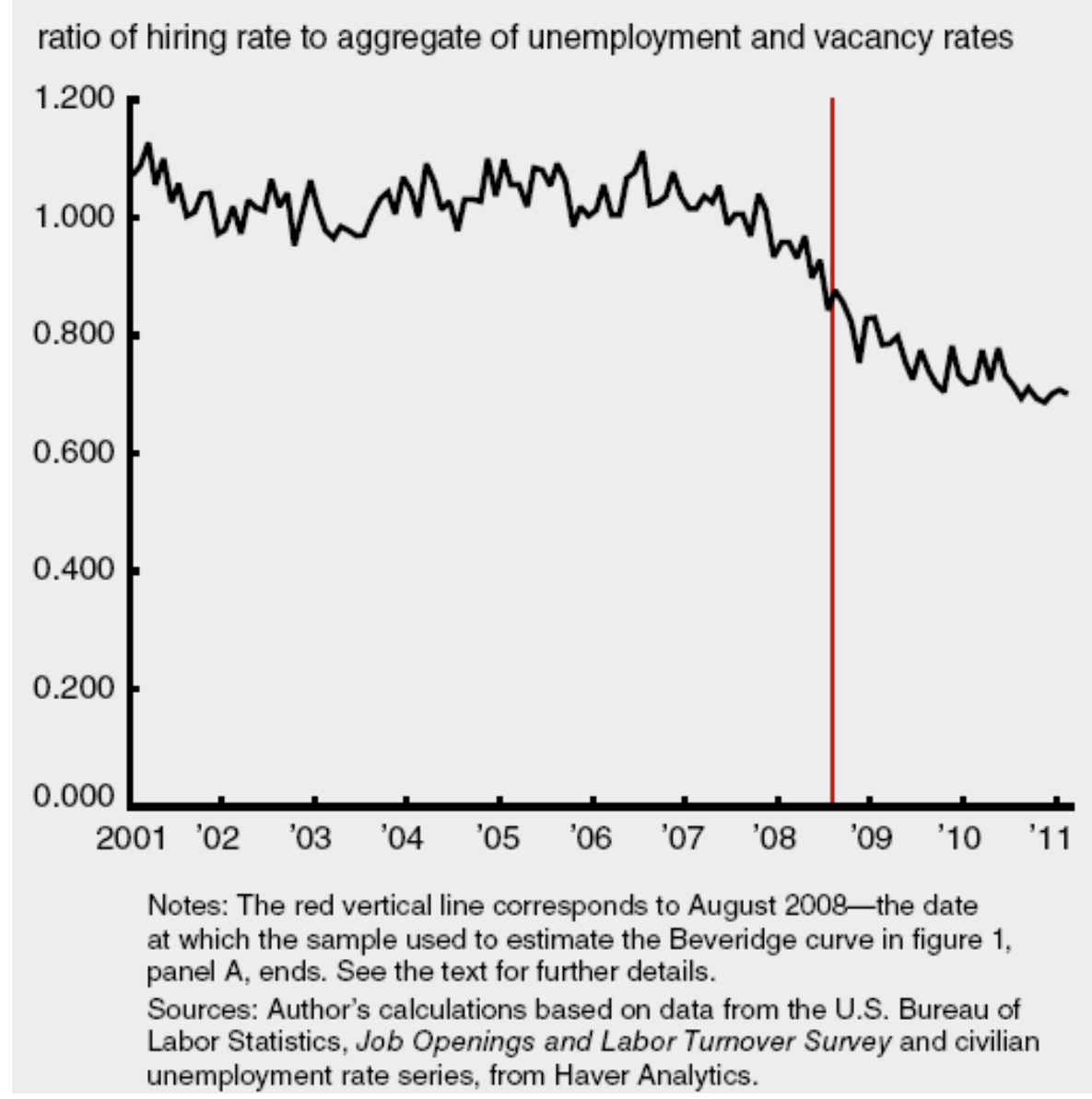

Source: Figure 3 in Gadi Barlevy, "Evaluating the Role of Labor Market Mismatch in Rising Unemployment." Economic Perspectives 35(3): 82-96. 
Figure 4: Average Values of Gross Stocks and Flows for Employment, Unemployment, and Not in the Labor Force, Oct 1995-Sept 2012

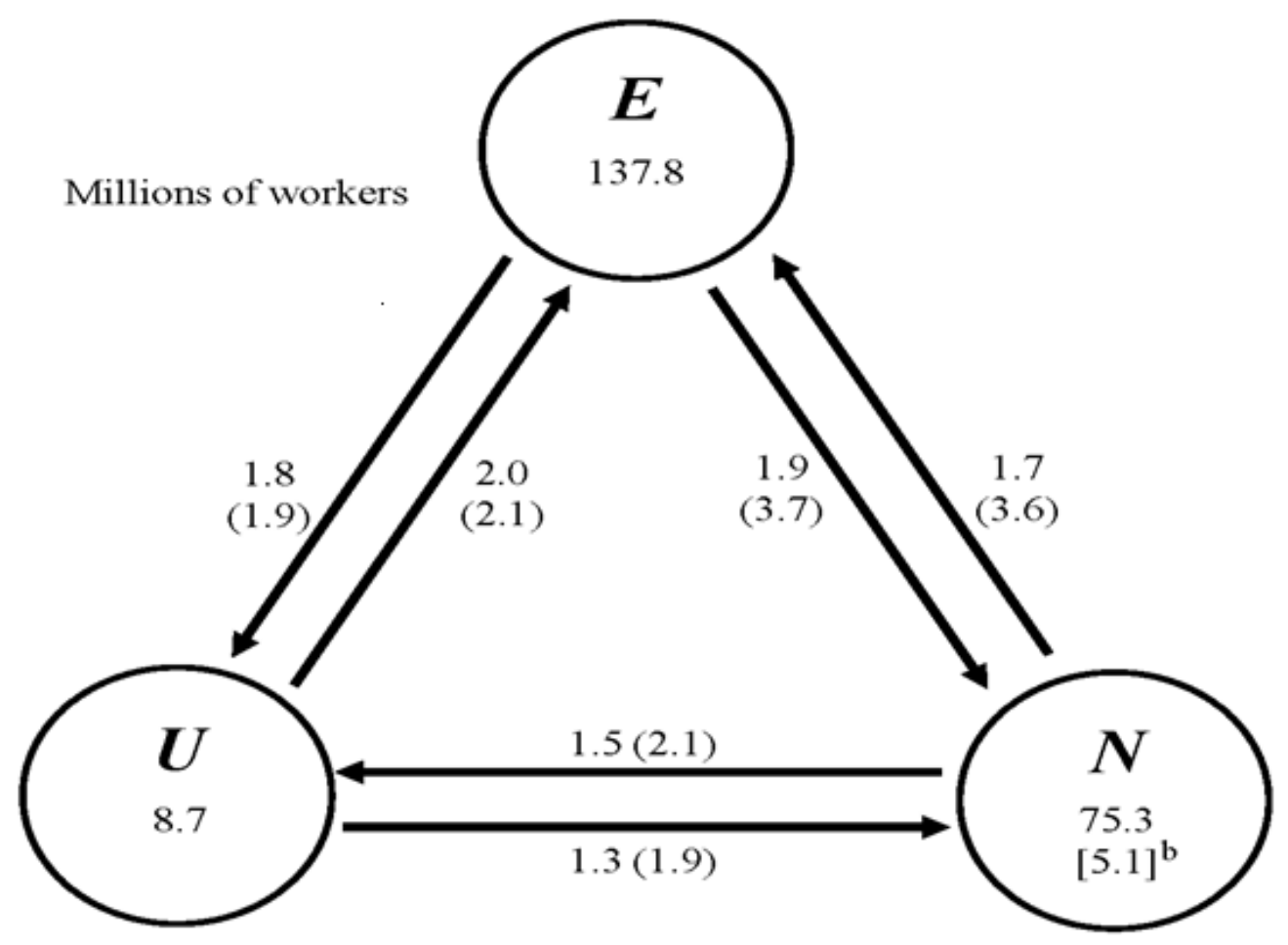

Source: Current Population Survey Labor Force Flows.

Note: Flow data are Abowd-Zellner adjusted. The original unadjusted published numbers appear in parentheses. All numbers are averages from October 1995 through September 2012 of monthly non-seasonally adjusted observations and are millions of persons.

a. The variables $E, U$, and $N$, represent employment unemployment, and not in the labor force respectively.

b. The bracketed stock figure for $N$ equals the number of people who report they want a job. 


\section{Figure 5: The Beveridge Curve (job openings vs. U6 unemployment rate}

(Seasonally Adjusted)

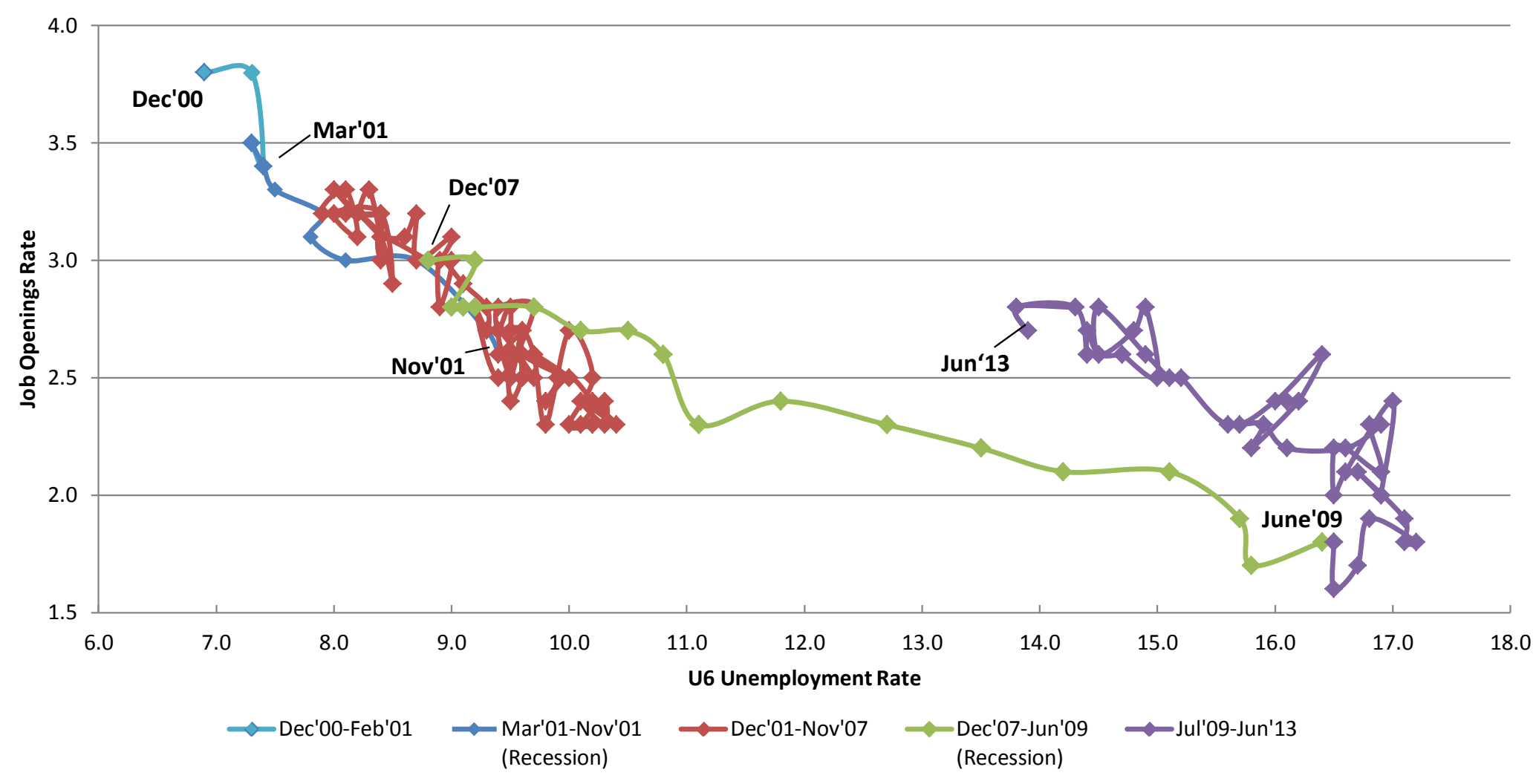

Source: Bureau of Labor Statistics, Current Population Survey, Job Openings and Labor Turnover Survey, and Haver Analytics. 
Figure 6: Ratio of Flows into Employment, 1990:2-2013:7

Three-Month Moving Average

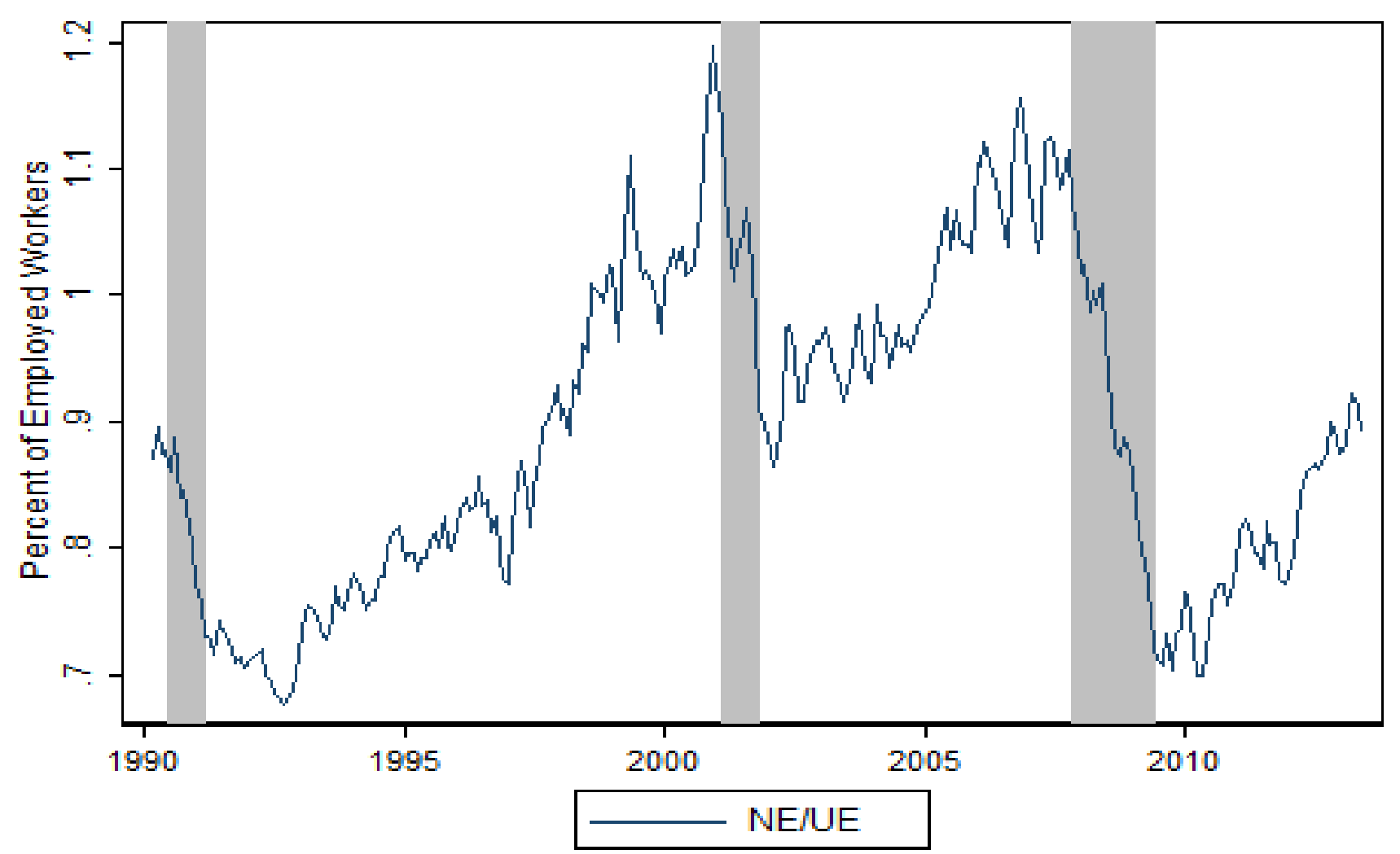

Source: CPS data from Haver Analytics; flows adjusted using multiplicative factors from Bleakley, Ferris, and Fuhrer (1999). 
Figure 7: Ratio of Flows out of Employment, 1990:2-2013:7

Three-Month Moving Average

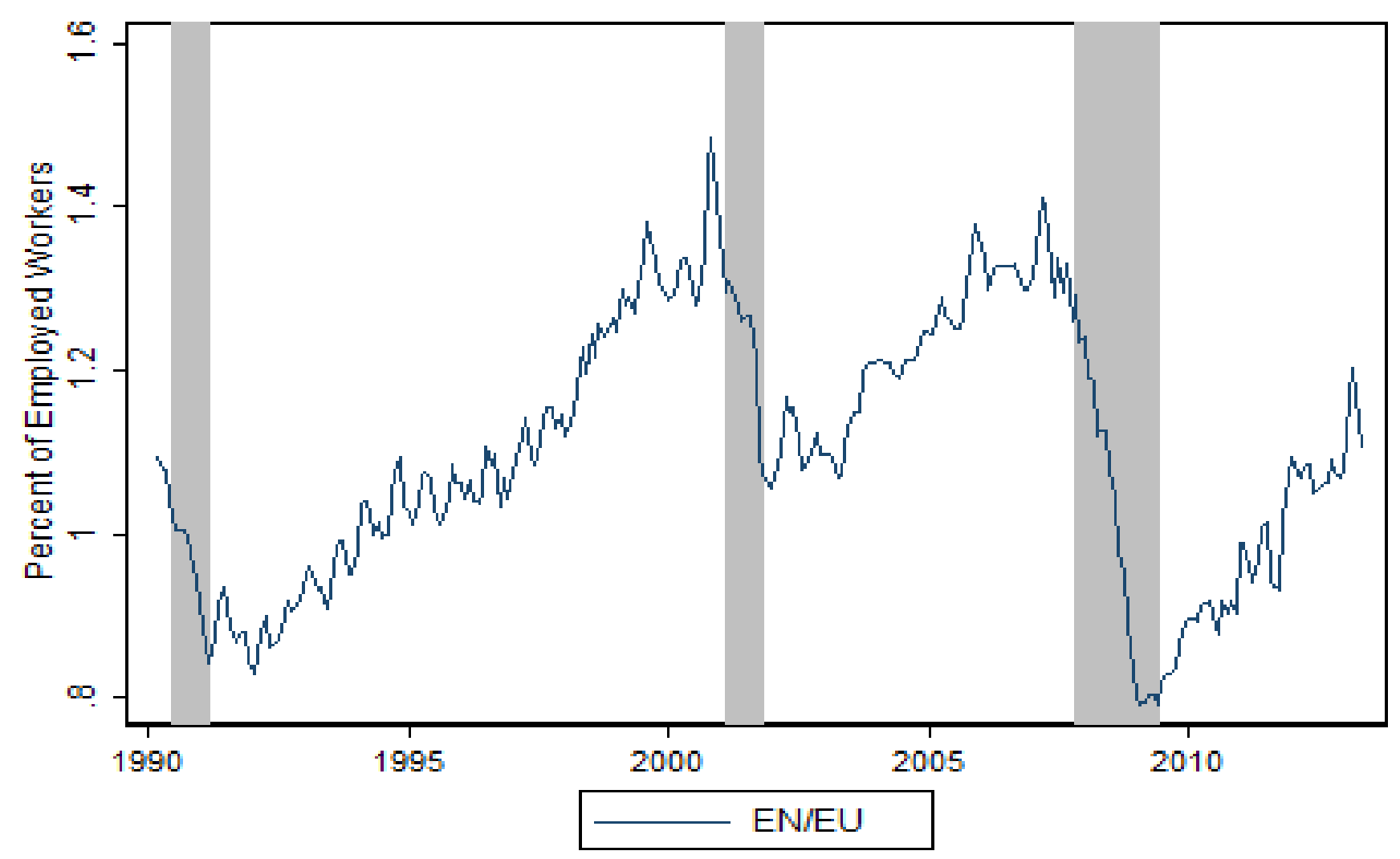

Source: CPS data from Haver Analytics; flows adjusted using multiplicative factors from Bleakley, Ferris, and Fuhrer (1999). 
Figure 8: Change of the Unemployment Rate from the Start of the Rise of the Aggregate Unemployment Rate, by Recession

(start of the rise - eight quarters after the peak)

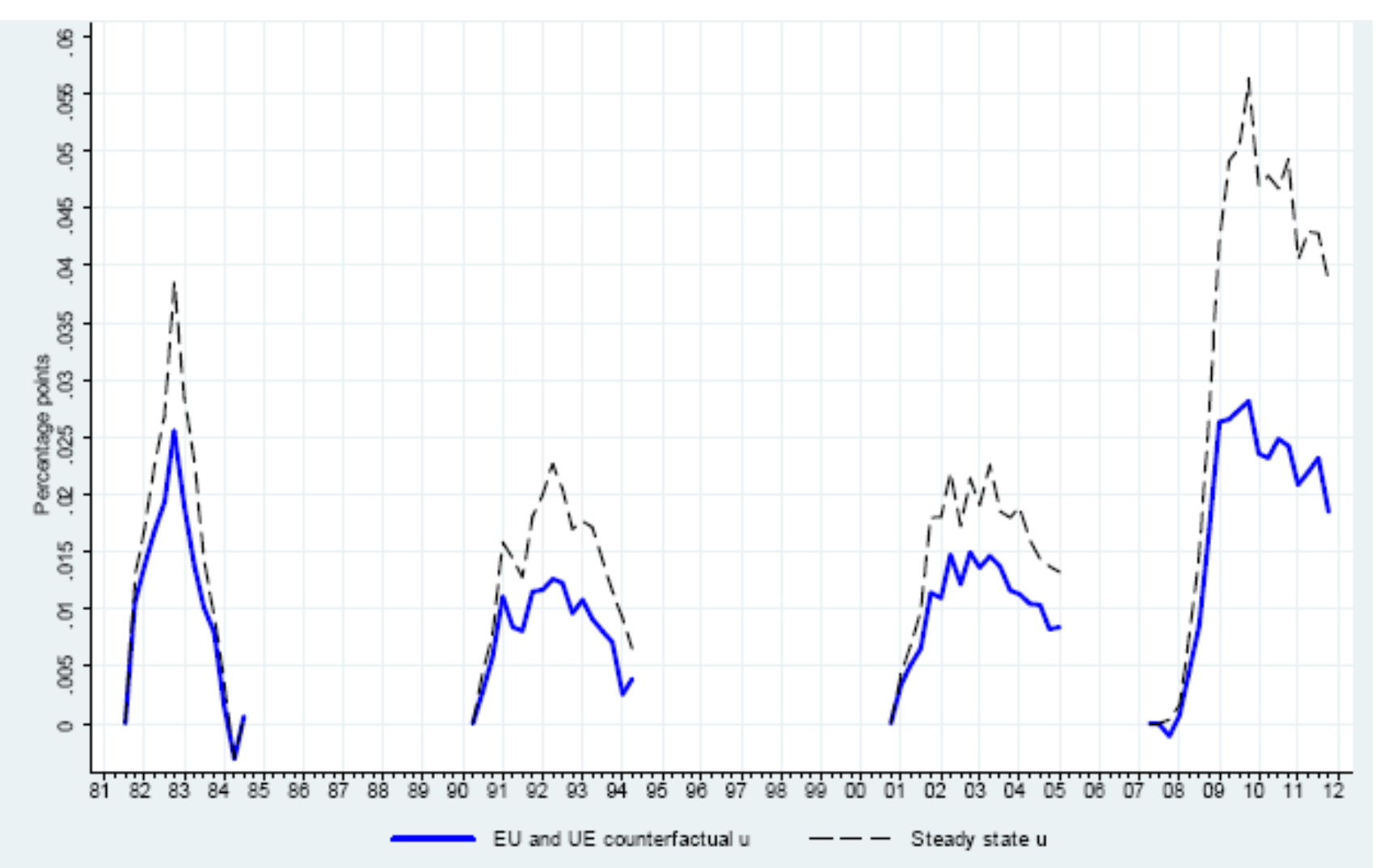

Source: Figure 2 in Marianna Kudlyak and Felipe Swartzman, "Accounting for Unemployment in the Great Recession: Nonparticipation Matters," Working Paper 12-04: Richmond, Federal Reserve Bank of Richmond. 


\section{Figure 9: Gross Flows among Labor Market States with EE Flows, October 1995-September 2012 (percent of population and percent of state in first month, monthly)}

\begin{tabular}{|c|c|c|c|c|}
\hline \multirow{3}{*}{ State in first month } & \multicolumn{4}{|c|}{ State in Second Month } \\
\hline & Same employer & New employer & Unemployed & NLF \\
\hline & \multicolumn{4}{|c|}{ As a Percent of Population } \\
\hline Employed & 58.5 & 1.4 & 0.8 & 1.6 \\
\hline Unemployed & & 0.9 & 2.0 & 0.9 \\
\hline NLF & & 1.5 & 0.9 & 31.5 \\
\hline \multicolumn{5}{|c|}{ As a Percent of State in First Month } \\
\hline Employed & 93.9 & 2.2 & 1.3 & 2.6 \\
\hline Unemployed & & 25.5 & 51.7 & 22.8 \\
\hline NLF & & 4.5 & 2.5 & 92.9 \\
\hline
\end{tabular}




\section{Figure 10: Total Dominant Job Separations by Non-employment}

1998:2-2010:2 (in thousands)

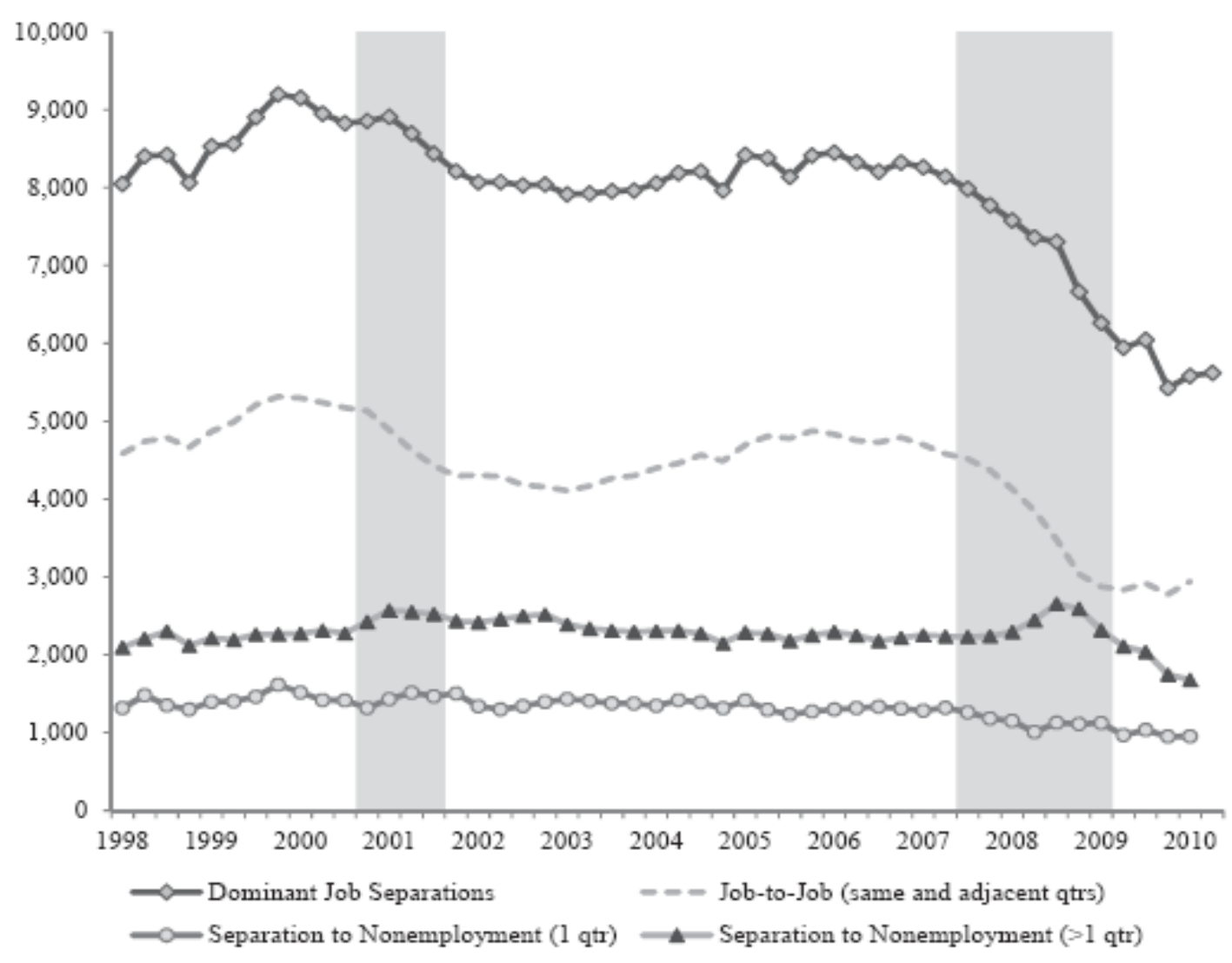

Source: Figure 1 in Henry Hyatt and Erica McEntarfer, "Job-To-Job Flows and the Business Cycle," Center for Economic Studies Paper 12-04, (March). Washington, D.C: U.S. Bureau of the Census. 2012. Notes: Shaded areas denote NBER recession quarters. Calculated from LEHD microdata, national employment histories for workers in nine states. 
Figure 11: Quits and Layoffs and Discharges

(Seasonally adjusted, in thousands)

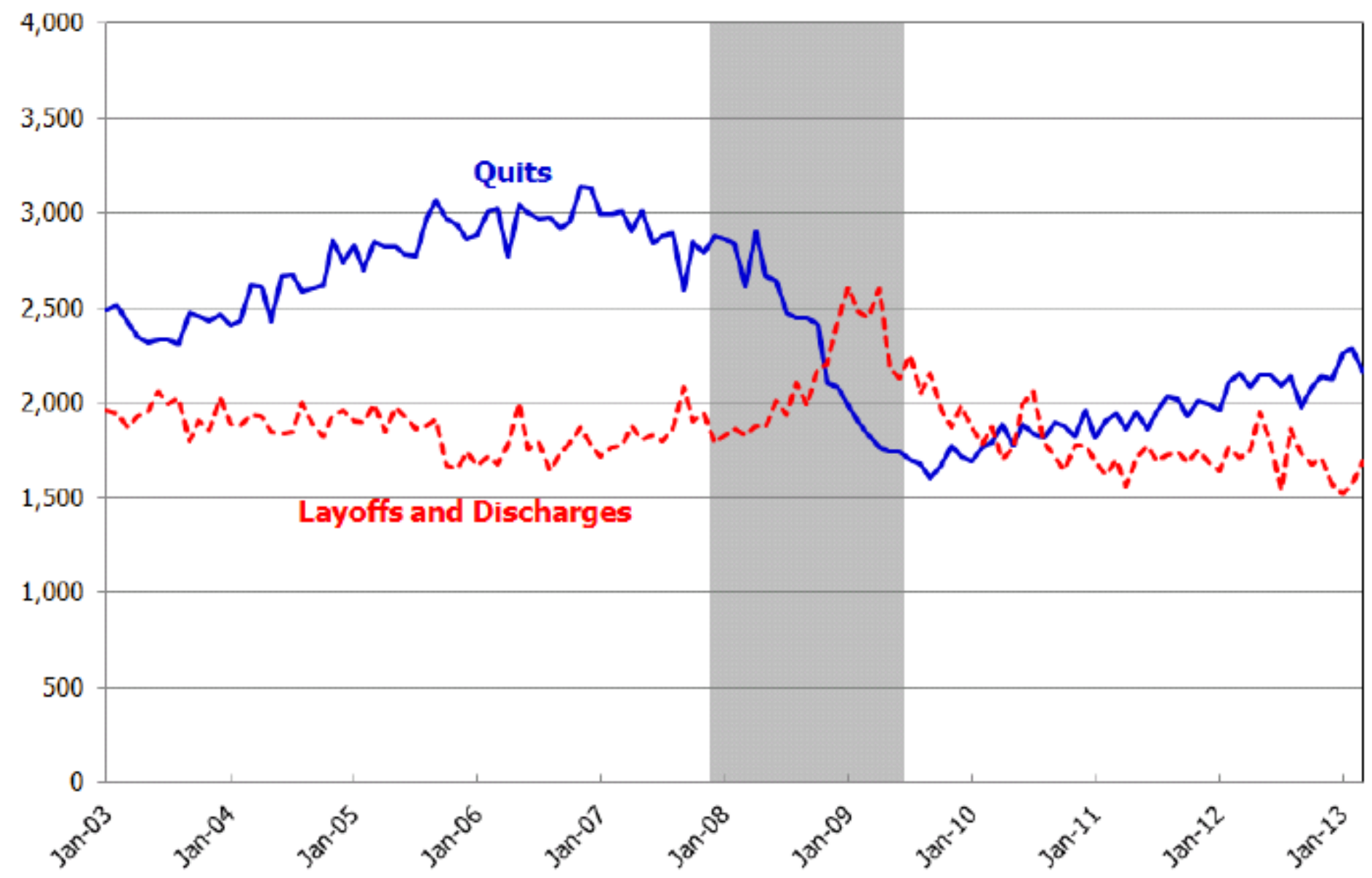

Source: Bureau of Labor Statistics, Current Population Survey, and Job Openings and Labor Turnover Survey, May 7, 2013. 


\section{Figure 12: Quits, Layoffs, and Job Destruction}

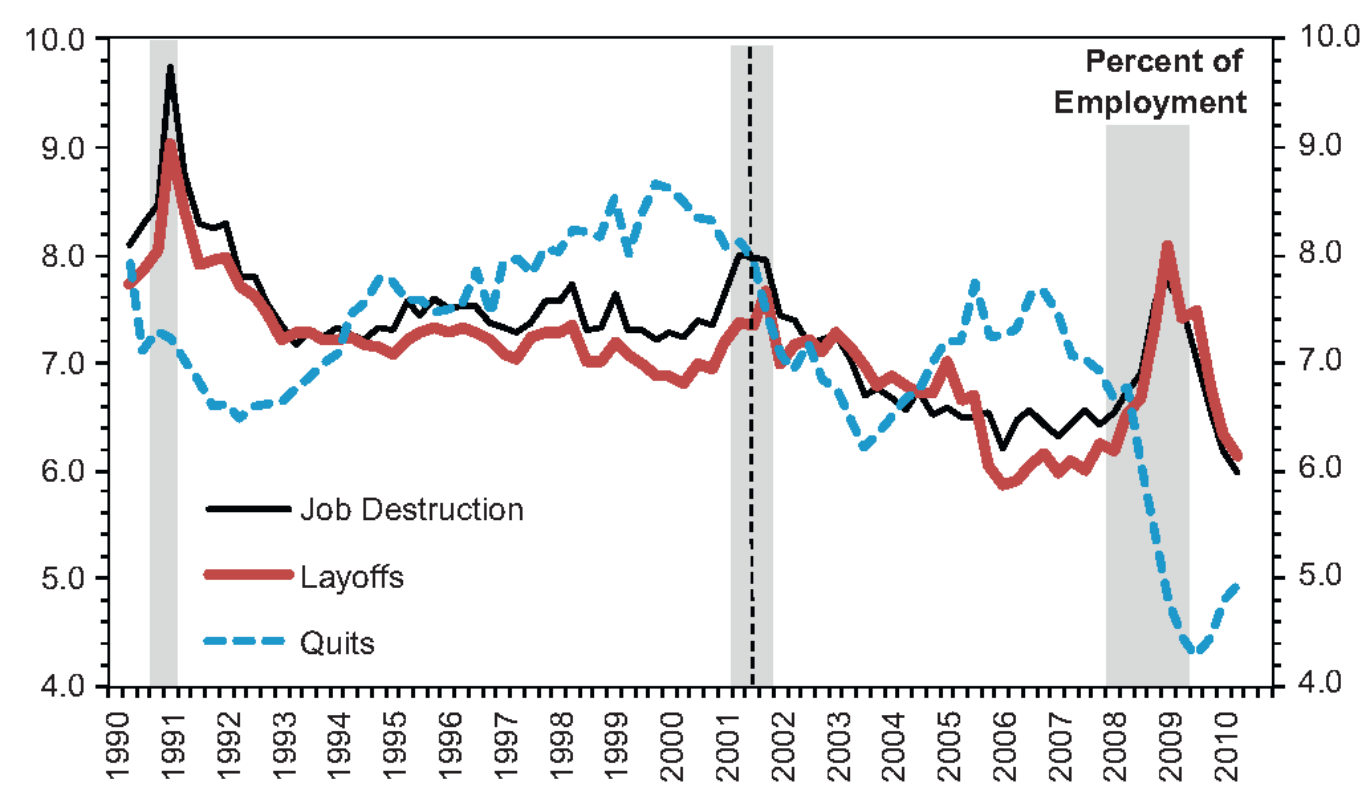

Fig. 1. Quits, layoffs, and job destruction.

Sources: Quit and layoff rates (2001Q3-2010Q2) are authors' calculations using JOLTS establishment microdata weighted to an aggregate value for each quarter using growth rate densities from the BED. Job destruction rates (1990Q2-2010Q2) are authors' tabulations directly from the BED data. All estimates are seasonally adjusted. All rates are percentages of employment. Backcasted estimates of the quit and layoff rates are included to the left of the dashed vertical line.

Source: Figure 1 in Steven J. Davis, R. Jason Faberman, and John C. Haltiwanger, "Labor Market Flows in the Cross Section and Over Time." Journal of Monetary Economics 59(1): 1-18. 


\section{Figure 13: Results of Hiring Dynamics Model by Industry, Size, and Turnover}

\begin{tabular}{|c|c|}
\hline & $\begin{array}{c}\text { Mean Vacancy } \\
\text { Duration } \\
1 / f_{t} \text { (in days) }\end{array}$ \\
\hline Nonfarm Employment & 20.0 \\
\hline \multicolumn{2}{|c|}{ Major Industry } \\
\hline Natural Resourses \& Mining & 12.8 \\
\hline Construction & 8.3 \\
\hline Manufacturing & 19.3 \\
\hline Transport, Wholesale, Utilities & 19.1 \\
\hline Retail Trade & 13.7 \\
\hline Information & 32.0 \\
\hline FIRE & 29.0 \\
\hline Professional \& Business Services & 20.4 \\
\hline Health \& Education & 35.4 \\
\hline Leisure \& Hospitality & 14.6 \\
\hline Other Services & 18.8 \\
\hline Government & 31.4 \\
\hline \multicolumn{2}{|c|}{ Establishment Size Class } \\
\hline 0-9 Employees & 16.5 \\
\hline 10-49 Employees & 15.2 \\
\hline 50-249 Employees & 17.1 \\
\hline 250-999 Employees & 24.1 \\
\hline 1,000-4,999 Employees & 37.9 \\
\hline 5,000+ Employees & 38.9 \\
\hline \multicolumn{2}{|c|}{ Worker Turnover Category } \\
\hline First Quintile (lowest turnover) & 87.9 \\
\hline Second Quintile & 52.8 \\
\hline Third Quintile & 32.8 \\
\hline Fourth Quintile & 18.4 \\
\hline Fifth Quintile (highest turnover) & 8.7 \\
\hline
\end{tabular}

Source: Table 3 in Steven J. Davis, R. Jason Faberman, and John C. Haltiwanger, "The Establishment-Level Behavior of Vacancies and Hiring." Quarterly Journal of Economics 128(2): 581-622. 
Figure 14: Vacancy Yields and Establishment Growth in the Cross Section, JOLTS Data

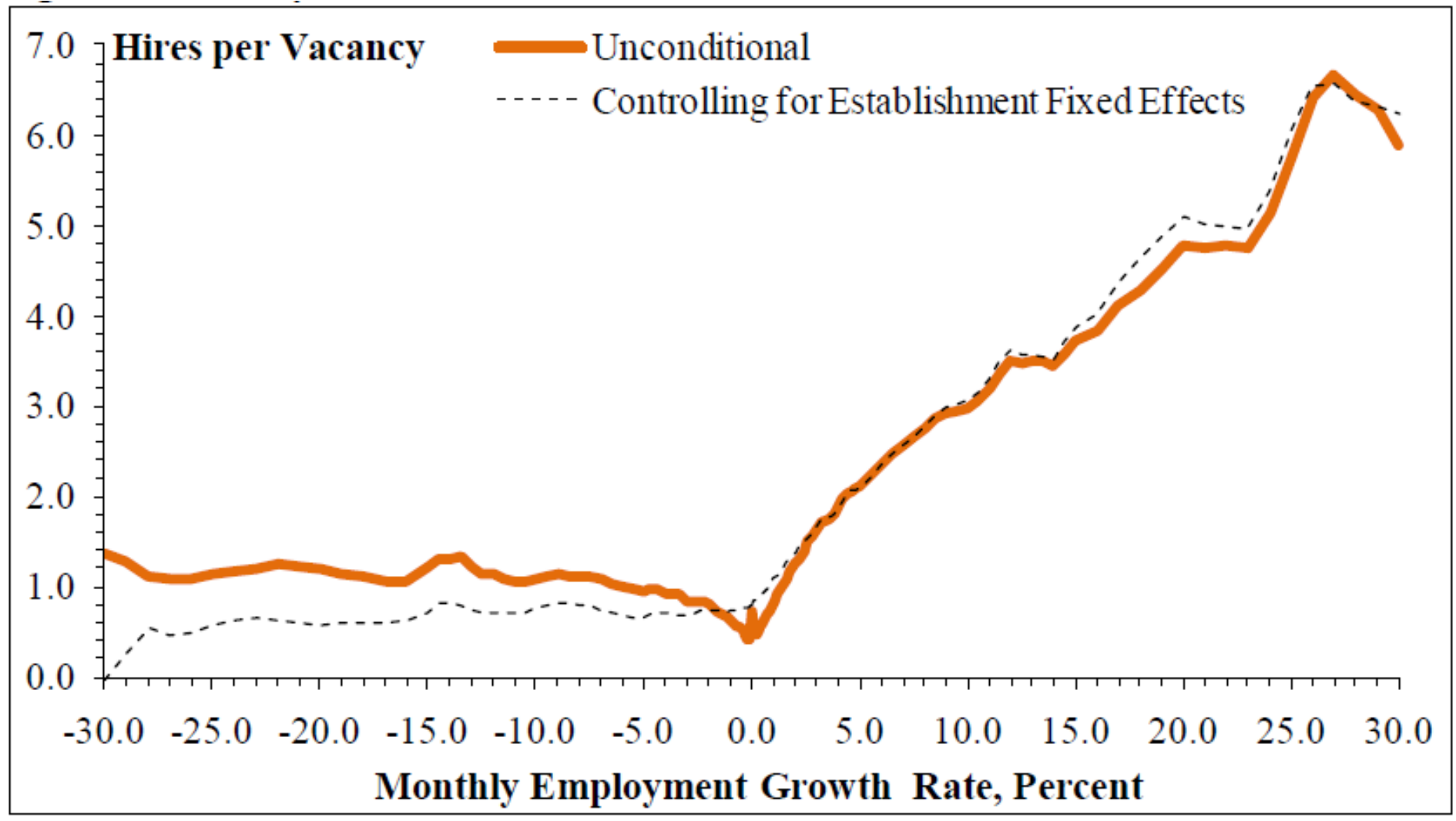

Note: The figure shows the cross-sectional relationship of the vacancy yield, as fit by nonparametric regression to approximately 577,000 monthly establishment-level observations.

Source: Figure 5 in Steven J. Davis, R. Jason Faberman, and John C. Haltiwanger, "The Establishment-Level Behavior of Vacancies and Hiring." Quarterly Journal of Economics 128(2): 581-622. 


\section{Figure 15: Job-Filling Rate and Recruiting Intensity per Vacancy January 2001 to September 2011}

— Recruiting Intensity (left axis) - --- Job-Filling Rate (right axis)

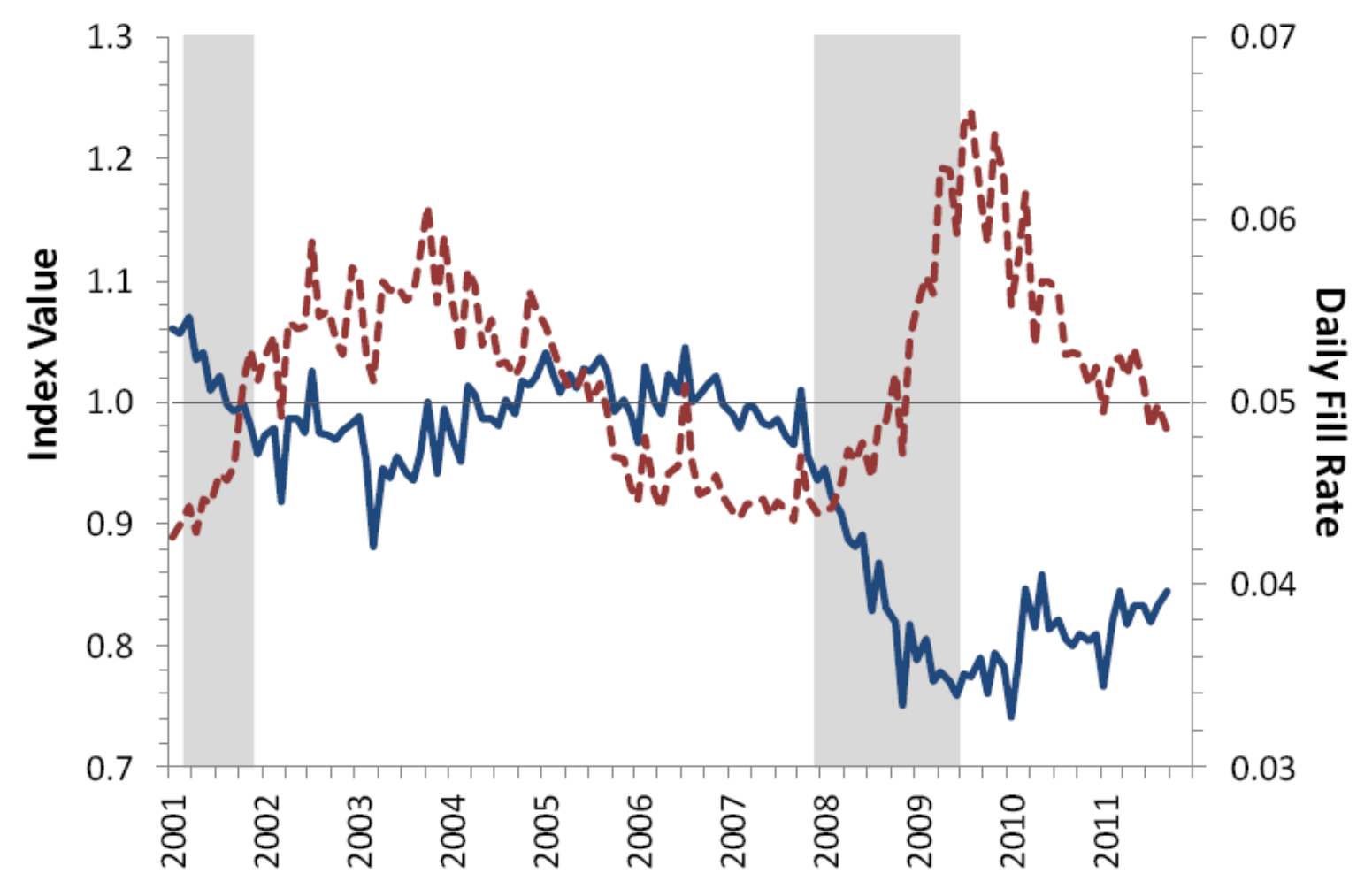

Source: Figure 1 in Steven J. Davis, R. Jason Faberman, and John C. Haltiwanger, "Recruiting Intensity during and after the Great Recession: National and Industry Evidence." American Economic Review: Papers and Proceedings 102(3): 584-588.

Notes: Authors' calculations using JOLTS micro data. See text and DFH for descriptions of how to calculate the job-filling rate and recruiting intensity per vacancy. Recruiting intensity is scales so that its 2004-07 average equals one. Shaded areas show NBER recessions. 
Figure 16: Measures of Inverse Market Tightness, January 2001 to December 2011

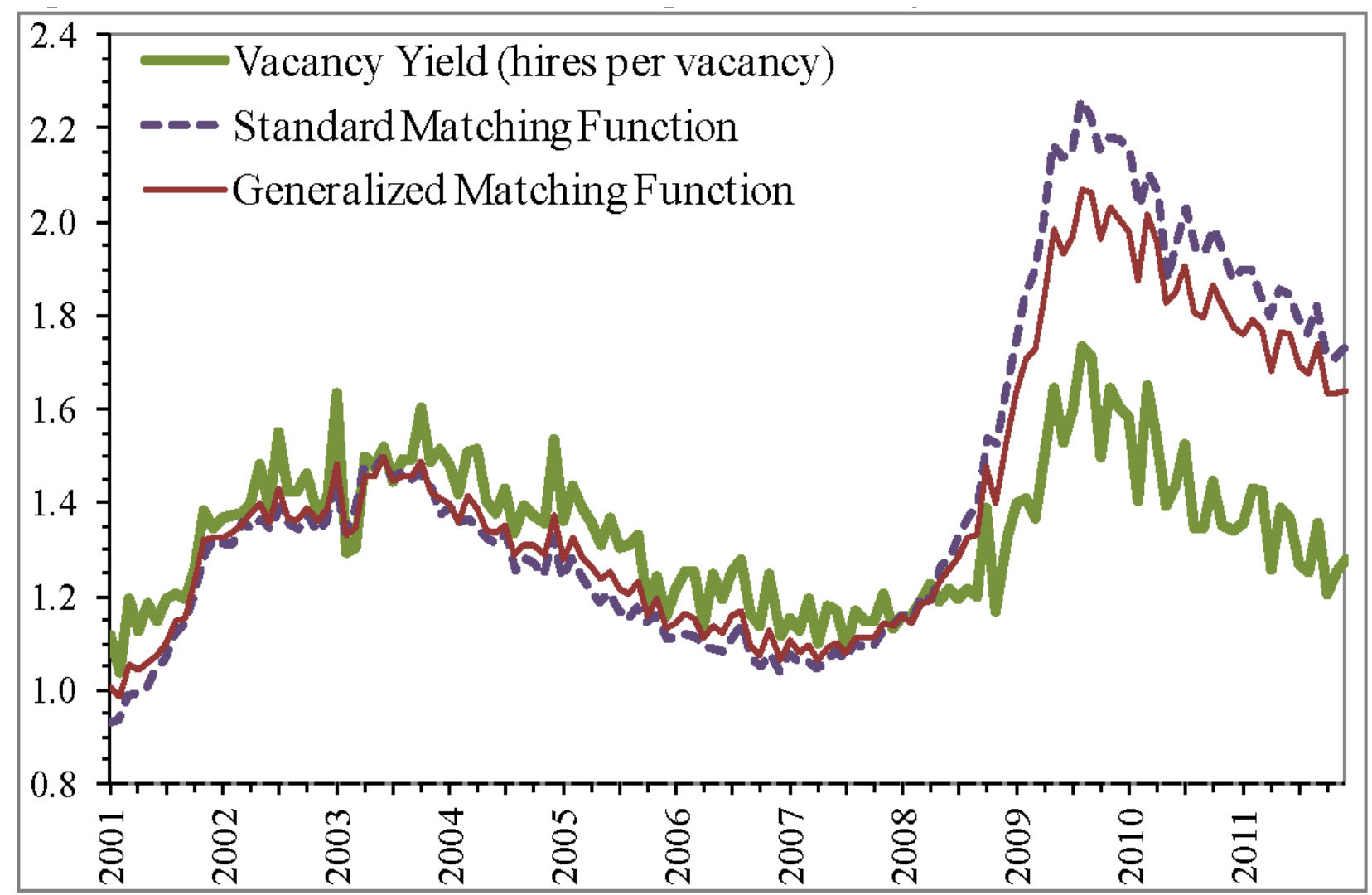

Note: Authors' calculations using published JOLTS data for nonfarm hires and vacancies and CPS data for civilian unemployment.

Source: Figure 1 in Steven J. Davis, R. Jason Faberman, and John C. Haltiwanger, "The Establishment-Level Behavior of Vacancies and Hiring." Quarterly Journal of Economics 128(2): 581-622. 